association. Another explanation could be the higher prevalence of ACE inhibitor-induced cough in Chinese subjects, as shown by CHAN et al. [6]. It is possible that ACE inhibitors are also protective in non-Asian populations. However, larger populations may be necessary to confirm such an effect.

Further studies on the relationship between angiotensinconverting enzyme and pneumonia in predominantly white populations are currently being undertaken in our department.

\section{E.M.W. van de Garde}

Utrecht Institute for Pharmaceutical Sciences, Utrecht, The Netherlands.

\section{REFERENCES}

1 Sekizawa K, Ujiie Y, Itabashi S, Sasaki H, Takishima T. Lack of cough reflex in aspiration pneumonia. Lancet 1990; 335: 1228-1229.
2 Nakagawa T, Sekizawa K, Arai H, et al. High incidence of pneumonia in elderly patients with basal ganglia infarction. Arch Intern Med 1997; 157: 321-324.

3 Arai T, Yasuda Y, Toshima S, Yoshimi N, Kashiki Y. ACE inhibitors and pneumonia in elderly people. Lancet 1998; 352: 1937-1938.

4 Ohkubo T, Chapman N, Neal B, et al. Effects of an angiotensinconverting enzyme inhibitor-based regimen on pneumonia risk. Am J Respir Crit Care Med 2004; 169: 1041-1045.

5 Arai T, Sekizawa K, Ohrui T, et al. ACE inhibitors and protection against pneumonia in elderly patients with stroke. Neurology 2005; 64: 573-574.

6 Chan WK, Chan TY, Luk WK, et al. A high incidence of cough in Chinese subjects treated with angiotensin converting enzyme inhibitors. Eur J Clin Pharmacol 1993; 44: 299-300.

\title{
PDE-5 inhibitors lower portal and pulmonary pressure in portopulmonary hypertension
}

\section{To the Editors:}

Several studies have proved that inhibitors of phosphodiesterase (PDE) 5 are potent compounds for lowering pulmonary pressure in pulmonary arterial hypertension. With great interest we read the study conducted by REICHENBERGER et al. [1] about the effect of sildenafil on portopulmonary hypertension (PPHTN). This is a specific condition characterised by an elevated pulmonary arterial pressure (PAP), increased pulmonary vascular resistance and a normal wedge pressure in a setting of underlying portal hypertension. Effective medical therapy is of great importance, as a markedly increased pulmonary pressure has a very poor prognosis in cirrhotic patients and is a contraindication for liver transplantation. The results of the studies by REICHENBERGER et al. [1] and others [2, 3] show that in these patients, inhibitors of PDE5 also lower PAP. However, REICHENBERGER et al. [1] focused on the effect of sildenafil on PAP; the potential effect of this drug on portal pressure was not investigated.

In a recent study, we showed that the PDE5 inhibitor vardenafil lowers portal pressure and increases portal blood flow in healthy subjects as well as in patients with liver cirrhosis [4]. We also found that sildenafil and tadalafil had similar effects (unpublished data). Recently, we investigated the acute effect of tadalafil on portal and pulmonary haemodynamics simultaneously in a patient with PPHTN.

In the 55-yr-old patient, alcoholic Child A cirrhosis had been diagnosed 7 yrs before. Alcohol consumption had stopped since cirrhosis was diagnosed. The reason for admission was increasing dyspnoea at physical exercise. The patient was taking no medication at the time of the study. The patient was obese $(186 \mathrm{~cm}, 108 \mathrm{~kg}$, body mass index 31.2), his blood pressure was $140 / 105 \mathrm{mmHg}$ and his cardiac frequency was $79 \mathrm{bpm}$. ECG and Doppler echocardiogram showed right heart enlargement with systolic PAP $\sim 75 \mathrm{mmHg}$. Spirometry showed a normal vital capacity $(5.3 \mathrm{~L}, 103 \%)$ and forced expiratory volume in one second $(3.3 \mathrm{~L}, 86 \%)$. Abdominal duplexsonography showed a slow $\left(9 \mathrm{~cm} \cdot \mathrm{s}^{-1}\right)$ and reduced portal flow, $\sim 0.15 \mathrm{~L} \cdot \mathrm{min}^{-1}$ with intrahepatic retrograde perfusion. The umbilical vein was reopened and a large splenorenal shunt was detected. Second-grade oesophageal varices were found on endoscopy.

After counselling the local ethics committee, we investigated the effect of tadalafil, a selective inhibitor of PDE5, on portal and pulmonary haemodynamics. Catheters were introduced into the pulmonary artery and one of the liver veins simultaneously. Haemodynamic parameters were recorded every $15 \mathrm{~min}$ for $75 \mathrm{~min}$. After $10 \mathrm{mg}$ tadalafil, mean PAP was reduced from 45 to $38 \mathrm{mmHg}$ (fig. 1). Cardiac index increased from 3.02 to $3.24 \mathrm{~L} \cdot \mathrm{min}^{-1} \cdot \mathrm{m}^{-2}$ and pulmonary vascular resistance decreased from 459 to 351 dynes $\cdot \mathrm{s} \cdot \mathrm{cm}^{-5}$, while arterial oxygen pressure increased from 70.5 to $78.2 \mathrm{mmHg}$. Hepatovenous pressure gradient decreased from 10 to $7 \mathrm{mmHg}$ and systemic arterial pressure decreased from 167/ 89 to $152 / 87 \mathrm{mmHg}$. Our results show, that PDE5 inhibition reduces portal venous and PAP in this patient with PPHTN.

Portal hypertension in liver cirrhosis is caused by multiple factors, e.g. regenerative nodules and sinusoidal fibrosis, hyperdynamic splanchnic circulation, vasoactive substances and increased sinusoidal tonus due to diminished nitric oxide production and increased cyclic guanosine monophosphate (GMP) degradation [5, 6]. Inhibitors of PDE5 increase portal venous flow and lower portal pressure by inhibiting the degradation of cyclic GMP [4]. Pulmonary arterial hypertension has 


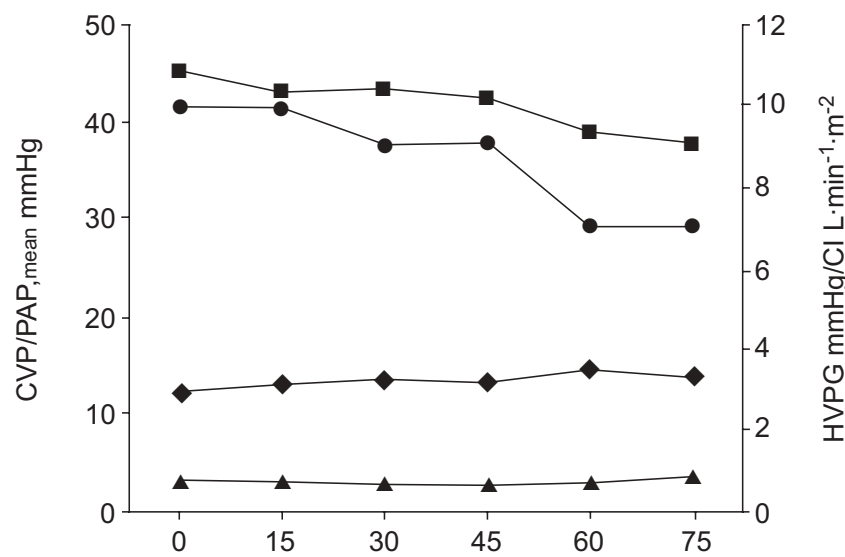

FIGURE 1. Reduction in mean pulmonary arterial pressure (PAP; $\mathbf{\square})$ and hepatovenous pressure gradient (HVPG; $\bullet$ ) under inhibition of phosphodiesterase 5 in a patient with portopulmonary hypertension. : cardiac index $(\mathrm{Cl})$; $\mathbf{\Delta}$ : central venous pressure (CVP).

been described in up to $16 \%$ of patients with portal hypertension (portopulmonary hypertension) [7]. In these patients the application of beta-blockers for therapy of portal hypertension may cause deleterious side-effects [8]. Use of inhibitors of PDE5 in patients with PPHTN would be a reasonable alternative if they prove to be effective in long-term studies. Inhibitors of PDE5 exert a direct dilating effect on pulmonary arteries in PPHTN. In addition, it may be speculated that a reduction of the portal pressure and improved hepatic perfusion diminish circulating vasoactive substances deteriorating pulmonary vascular remodelling.

In conclusion, by using inhibitors of phosphodiesterase 5 in portopulmonary hypertension, a double goal may be achieved: a reduction of elevated portal and pulmonary pressure simultaneously.
P. Deibert, H. Bremer, M. Roessle, A-K. Kurz-Schmieg and W. Kreisel

University of Freiburg, Freiburg, Germany.

\section{REFERENCES}

1 Reichenberger F, Voswinckel R, Steveling E, et al. Sildenafil treatment for portopulmonary hypertension. Eur Respir J 2006; 28: 563-567.

2 Chua R, Keogh A, Miyashita M. Novel use of sildenafil in the treatment of portopulmonary hypertension. J Heart Lung Transplant 2005; 24: 498-500.

3 Makisalo H, Koivusalo A, Vakkuri A, Hockerstedt K. Sildenafil for portopulmonary hypertension in a patient undergoing liver transplantation. Liver Transpl 2004; 10: 945-950.

4 Deibert P, Schumacher YO, Ruecker G, et al. Effect of vardenafil, an inhibitor of phosphodiesterase-5, on portal haemodynamics in normal and cirrhotic liver - results of a pilot study. Aliment Pharmacol Ther 2006; 23: 121-128.

5 Langer DA, Shah VH. Nitric oxide and portal hypertension: interface of vasoreactivity and angiogenesis. J Hepatol 2006; 44: 209-216.

6 Groszmann RJ, Abraldes JG. Portal hypertension: from bedside to bench. J Clin Gastroenterol 2005; 39: S125-S130.

7 Rodríguez-Roisin R, Krowka MJ, Hervé P, Fallon MB, on behalf of the ERS Task Force Pulmonary-Hepatic Vascular Disorders Scientific Committee ERS Task Force PHD Scientific Committee. Pulmonary-hepatic vascular disorders. Eur Respir J 2004; 24: 861-880.

8 Provencher S, Herve P, Jais X, et al. Deleterious effects of betablockers on exercise capacity and hemodynamics in patients with portopulmonary hypertension. Gastroenterology 2006; 130: $120-126$. 